\title{
Arsenic pollution in the southwest of Tuscany: monitoring of Cornia catchment basin
}

\author{
F. Rossi ${ }^{1}$, A. Donati ${ }^{1}$, M. Rustici ${ }^{2}$, B. Rugani ${ }^{1}$ \& E. Tiezzi ${ }^{1}$ \\ ${ }^{1}$ Department of Chemical and Biosystems Sciences, University of Siena, \\ Italy \\ ${ }^{2}$ Department of Chemistry, University of Sassari, Italy
}

\begin{abstract}
The territory of Colline Metallifere, in SW Tuscany, is characterized by the presence of strong arsenic anomalies. Some hypotheses, formulated in the last 20 years, based on geological and mineralogical factors have failed to explain the peculiar distribution of this toxic element in soil, fluvial sediments and ground water. Our research group has been studying for four years the problem of arsenic pollution in this district to investigate the origin and the mechanism of As diffusion in the environment. In particular we started a comparative study based on the extensive sampling of the stream sediments of the main waterways of Colline Metallifere (Pecora, Bruna and Cornia and their tributaries). In this work we focused our attention on the stream sediments and the soil of the Cornia basin. The comparative analysis of Cornia and the other rivers of the area, together with the investigation of historical series of data, provided important information about the origin of contamination of the territory and the impact of ancient mining settlements on this phenomenon.
\end{abstract}

Keywords: arsenic pollution, Tuscany, geochemical investigation, elemental analysis, anthropogenic activity.

\section{Introduction}

Arsenic is a naturally occurring element, with an average abundance that range from 1 to $10 \mathrm{mg} / \mathrm{kg}$ (dried soil) in the earth crust ranking as the 20th abundant element [1]. 
In a growing number of cases the concentration of this metalloid has been found much higher than average all around the world, and most of the time these anomalies were due to anthropogenic activities. The presence of As in the environment at high levels combined with its well known toxicity, has generated a large public concern and a widespread interest in the scientific community and government agencies for health and environment. In order to understand the diffusion routes of Arsenic in the environment and its biogeochemical cycle, a large number of publications on its chemistry in soil and ground water have been produced [2].

The present paper is a part of a wider project that has been started in order to understand the origin of the strong Arsenic contamination in the Scarlino plain in the southwest of Tuscany [3-6]. In this area, a partially filled wetland, close to the sea, a power plant for sulfuric acid production from pyrite roasting was installed in 1962. The plant used the ores found in the mine-field (Colline Metallifere), far about $15 \mathrm{~km}$ west from this site. In the last 20 years it has been clear that a large area around the industrial site was strongly contaminated (up to $1290 \mathrm{ppm}$ in the soil and $2700 \mathrm{ppb}$ in the ground water) by Arsenic compounds [7].

However, several chemists and geologists negate anthropogenic origins for these anomalies and formulated another alternative hypothesis which is related with the natural accumulation of the element via fluvial sediments and via underground hydrothermal water fluxes transported from mineralized area [8].

In previous papers $[5,6]$ we described the results of an extensive sampling of fluvial sediments collected from two very similar rivers and their tributaries, which flow almost parallel from the "Colline Metallifere" towards the coastal wetlands: the Pecora River and the Bruna River. From a comparative study of these two environments we were able to establish the extent of Arsenic natural background. Moreover we accumulated strong evidences of the importance of ancient mining and smelter sites in the formation of the environmental geochemistry as it is now.

In this paper we present the analysis of stream sediments and soil samples collected along the Cornia catchment basin, the third most important river of the area. Cornia shares similar geo-morphologic characteristics with the other two rivers, in particular it springs and streams in the same area and along its course it passes through some sites interesting from a geochemical point of view like spas or Tin mines. Moreover all three rivers end in geographically similar areas, even if Scarlino plain (Pecora's mouth), as mentioned above, is highly industrialized conversely to Diaccia Botrona (Bruna's mouth), which is a natural park and Bottegone marsh (Cornia's mouth), which is partly a WWF oasis but it also hosts a thermoelectric power plant.

The territory of Scarlino, considered together with the large area of the "Colline Metallifere", and other uncontaminated coastal wetlands which have same origin, presents indeed some unique features that could help to understand the general mechanisms of Arsenic diffusion. A deeper understanding of Arsenic mobility in particular in wetlands environment and the relationship with its bioavailability, is one of the recent most intriguing topics of scientific debate. 


\section{Materials and methods}

In our campaigns we collected more than 200 samples including stream sediments, soils and waters. In this work we focus our attention on the analysis of 71 samples of stream sediment and 53 samples of soil, collected in five sampling cycles during a period spanning from March to October 2004; for every sample $[\mathrm{As}],[\mathrm{Cd}],[\mathrm{Cr}],[\mathrm{Pb}]$ and $[\mathrm{Mn}]$ were recorded. The complete location of the samples is shown in fig. 1.

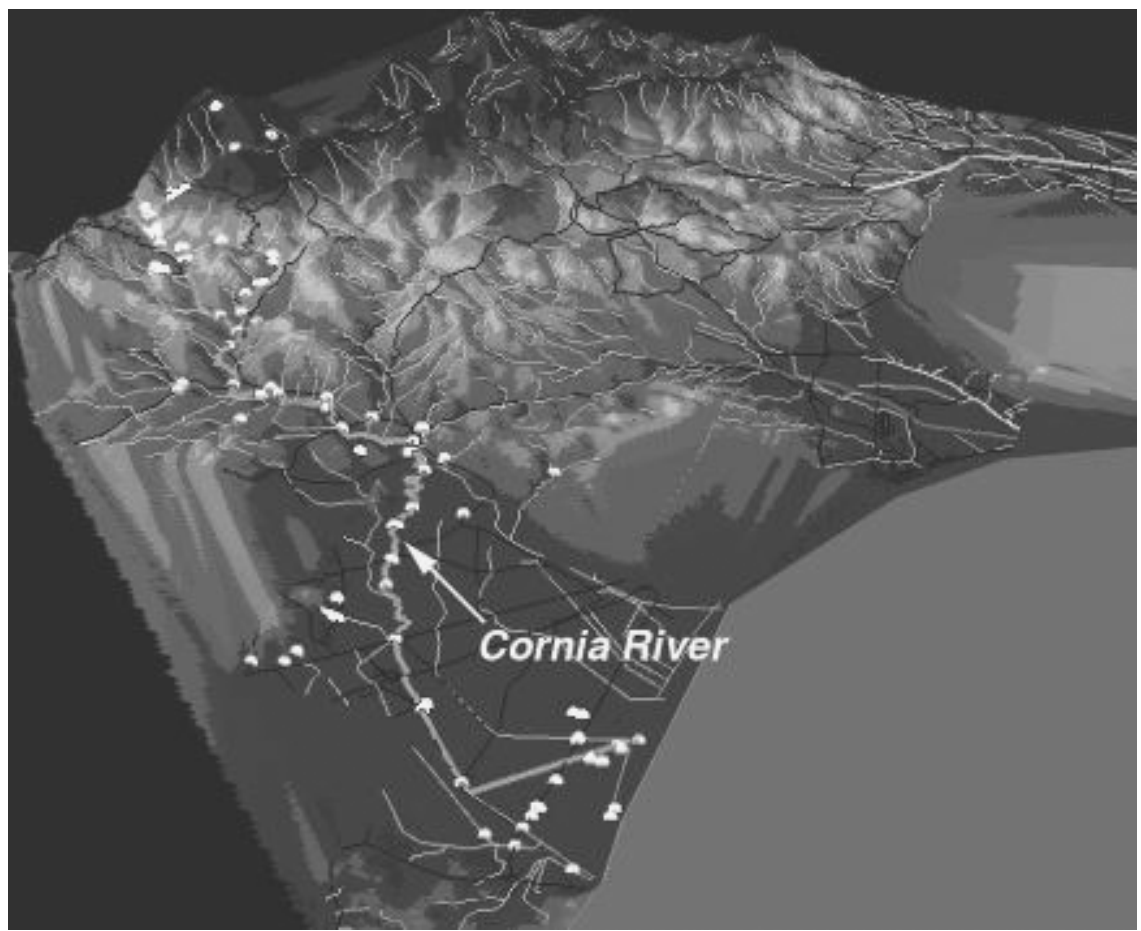

Figure 1: Study area. Dots indicate sampling points.

Samples of sediment were collected along the course of the Cornia River together with samples coming from its tributaries.

Dried stream sediments and soils were treated as follows: the fraction of 150 $\mu \mathrm{m}$ of the dried matter was homogenized and stored in sample stocks of about $100 \mathrm{~g}$. Sub-samples of about $150 \mathrm{mg}$ were subsequently weighted and digested with a mix of fluoridric, percloric, nitric and hydrochloric acid in a microwave oven. Pollutant concentrations were determined by "graphite furnace - atomic absorption spectroscopy" (GF-AAS). In the $30 \%$ of the sample stocks, three subsamples were extracted and in the $10 \%$ of the sample stocks, six sub-samples were extracted. For these sample stocks pollutant concentrations were given as the average of the concentration of the sub-samples. The difference of the 
measured values from the average is less than $10 \%$ in all the considered cases. The following standards were used for the instrument calibration: $1000 \mathrm{mg} / \mathrm{l} \mathrm{of}$ arsenic acid (As), $1000 \mathrm{mg} / \mathrm{l}$ of cadmium nitrate (Cd), $1000 \mathrm{mg} / \mathrm{l}$ of chromium nitrate, $1000 \mathrm{mg} / \mathrm{l}$ of lead nitrate $(\mathrm{Pb}), 1000 \mathrm{mg} / \mathrm{l}$ of manganese nitrate $(\mathrm{Mn})$, all dissolved in a $0,5 \mathrm{M}$ solution of nitric acid. All the acids used were of ultra-pure grade (Merk), all other chemicals were of analytical grade (Merk). Data are reported in ppm, which correspond to $\mathrm{mg}$ of an element in $1 \mathrm{~kg}$ of dried matter.

\section{Results}

In this section results of the analysis will be presented for every element. Only anomalous or particularly interesting values will be reported and commented for every element.

\subsection{Cadmium and manganese}

Cadmium concentration was very low in all samples analyzed; in most of the cases it was under the instrument detection limits, and in the other cases it was under the law limits, both in stream sediments and top soils. About manganese Italian law does not provide upper limits for its presence in water, soil or stream sediment. Its concentration was about $800 \mathrm{ppm}$ along the entire course of the river and in the terrains nearby, except for few spots in correspondence of the "Campigliese" mining zone, in which we found peaks of 1400-1600 ppm.

\subsection{Lead}

Italian law provides a lead concentration limit of $100 \mathrm{ppm}$ in stream sediments and $1000 \mathrm{ppm}$ in soils (for commercial and industrial purposes). About stream sediments only one anomalous value was found in "Botro Colombo" stream, a tributary of Cornia River. This high value (791.1 ppm) was probably due to the fact that "Botro Colombo" drains the archeominerary zone of Montioni. In all other samples a mean $[\mathrm{Pb}]$ of $30 \mathrm{ppm}$ was found.

Top soil analysis revealed high tenors of lead in the zone of "San Silvestro" Archeominerary Park, in particular [Pb] ranging from about $1200 \mathrm{ppm}$ to about $6500 \mathrm{ppm}$. Data recorded for lead concentration stand in line with the mean values of other archeominerary areas or industrial sites present in "Colline metallifere". Figure 2 shows trends of $[\mathrm{Pb}]$ along the river course.

\subsection{Chromium}

[Cr] tenors in Cornia (and tributaries) stream sediments are generally low. Exceptions to this behaviour were found in correspondence of hydrothermal springs and former mining districts. In particular, [Cr] ranges from 1560 to 4584 ppm in "Fosso Corniaccia" stream, which drains Venturina hydrothermal zone.

Regarding top soils, we found a distribution similar to stream sediments: in Venturina soils and near former tin mine "Sales" [Cr] ranges from 1400 to $1700 \mathrm{ppm}$. 


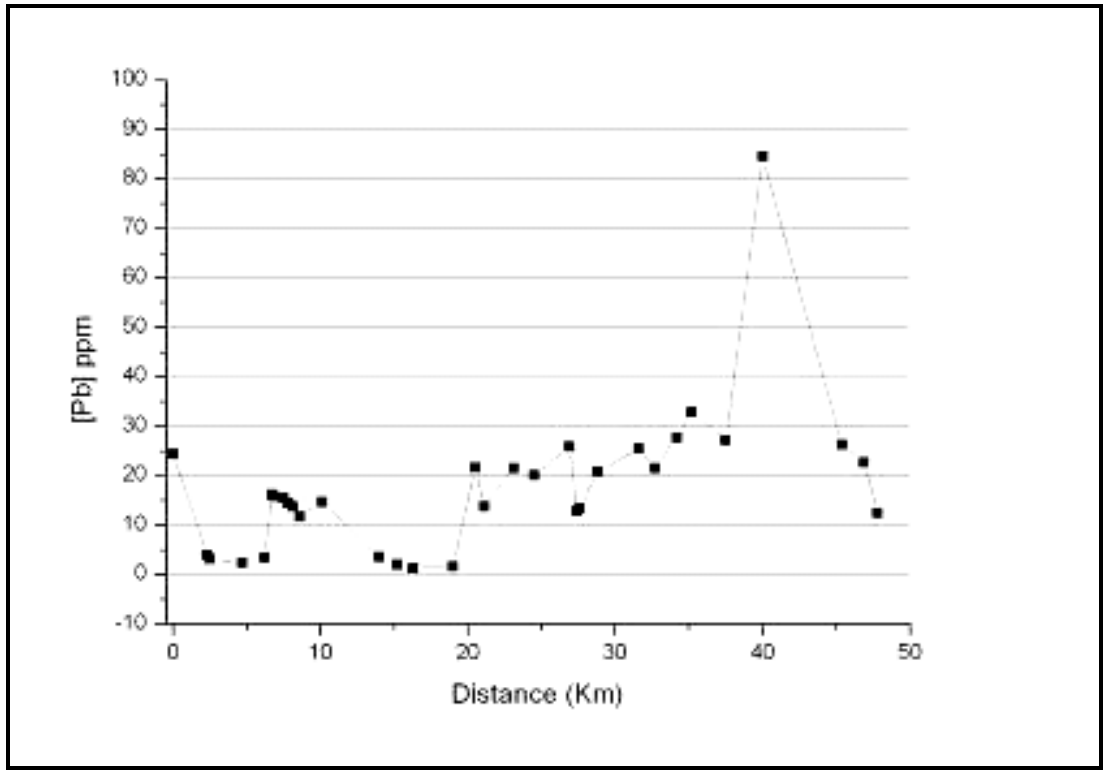

Figure 2: $\quad[\mathrm{Pb}]$ trend in stream sediments of Cornia River as a function of the distance from the spring. $[\mathrm{Pb}]$ tenor is low along the whole course of the river.

High [Cr] values in "Venturina" area are not explicable only in terms of hydrothermal or mining influences and need further investigations. Figure 3 shows the location of the anomalies, in the inset it is reported $[\mathrm{Cr}]$ trend along the main course of Cornia. It is evident from the figure that contamination of tributaries does not influence the pollution level of the main river.

\subsection{Arsenic}

Figures 4 and 5 show results for [As] analysis in upper and lower Cornia valley. The arsenic content is showed graphically with vertical bars for every sampling point. From figures it is evident that Cornia has generally low [As] tenors along the main course, but localized anomalies were found in its tributaries and in the soils nearby. Major anomalies are present in the upper valley, where [As] reaches 3327 ppm in "Mulino Nuovo" stream and 2047 ppm in the soils near "San Pompeo" power plant. These extremely high values are explicable in terms of hydrothermal water fluxes: "Mulino Nuovo" stream receives water from a hydrothermal spring, which is part of the Hellenistic-roman "Sasso Pisano" archeological complex; soils in the zone of San Pompeo are highly contaminated by the presence of geothermal power plant. It is interesting to note that anomalies are punctual and circumscribed to the pollutant sources. In fact stream sediments samples taken afterwards pollution sources present low level of [As] and generally, as in the case of chromium, [As] in Cornia river main stream is not influenced by the presence of punctual pollution sources. 


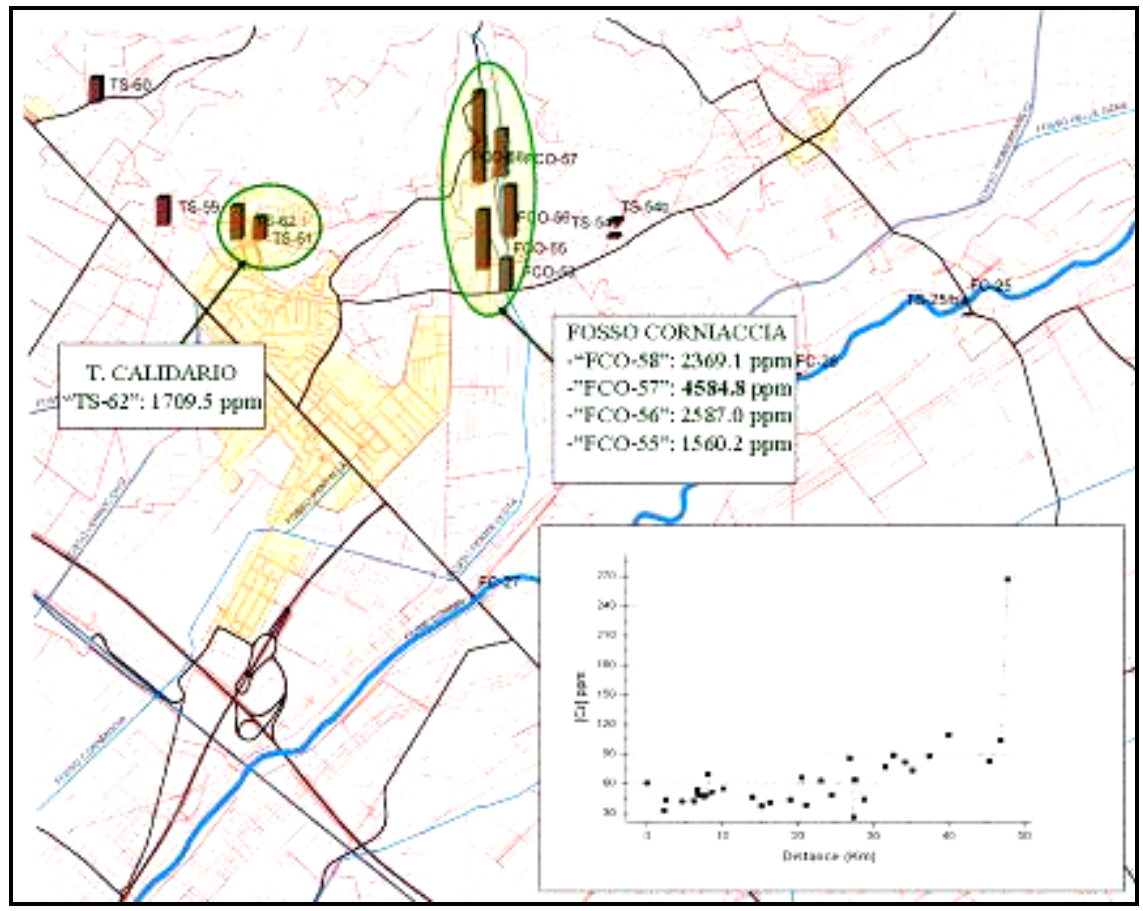

Figure 3: Figure shows the locations of the strong $\mathrm{Cr}$ anomalies. The inset reports $[\mathrm{Cr}]$ trend along the Cornia River course.

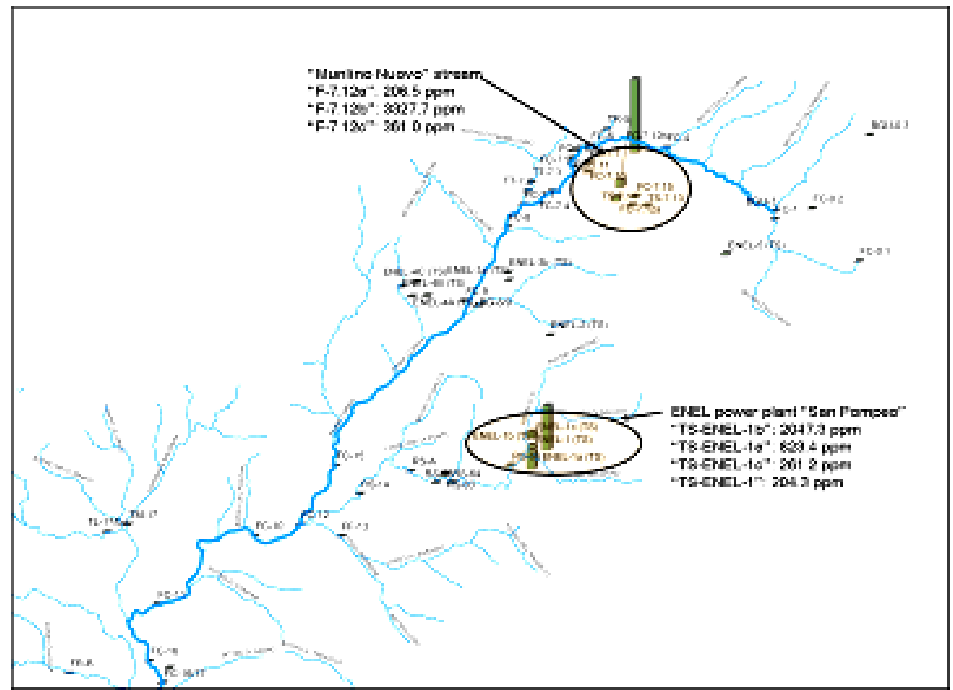

Figure 4: Upper Cornia valley. Circlets highlight anomalies area. 


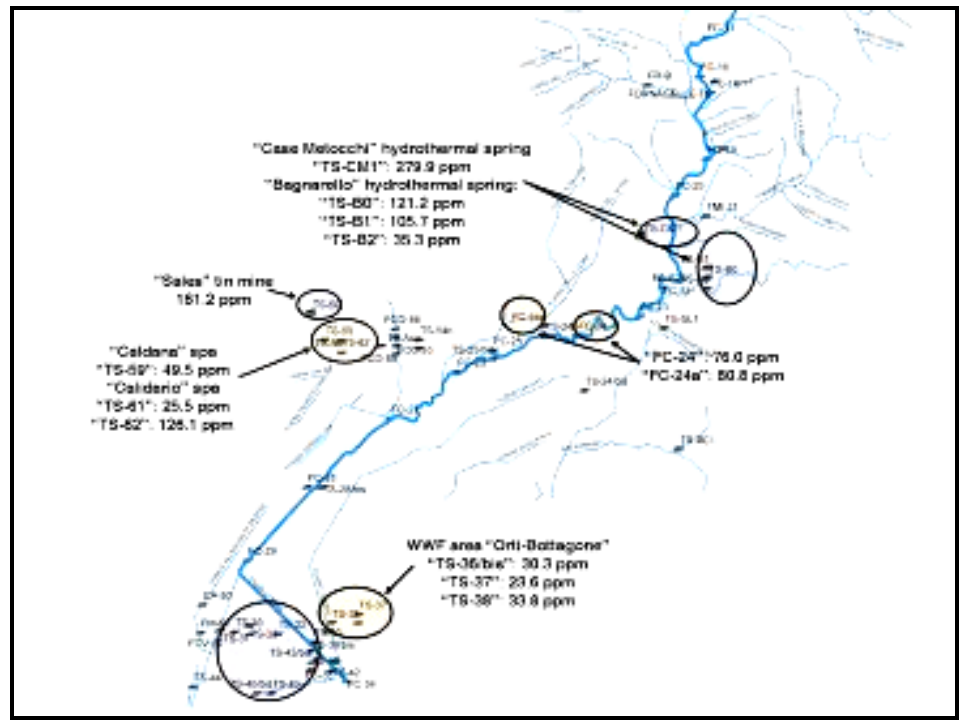

Figure 5: Lower Cornia valley. Circlets highlight anomalies area.

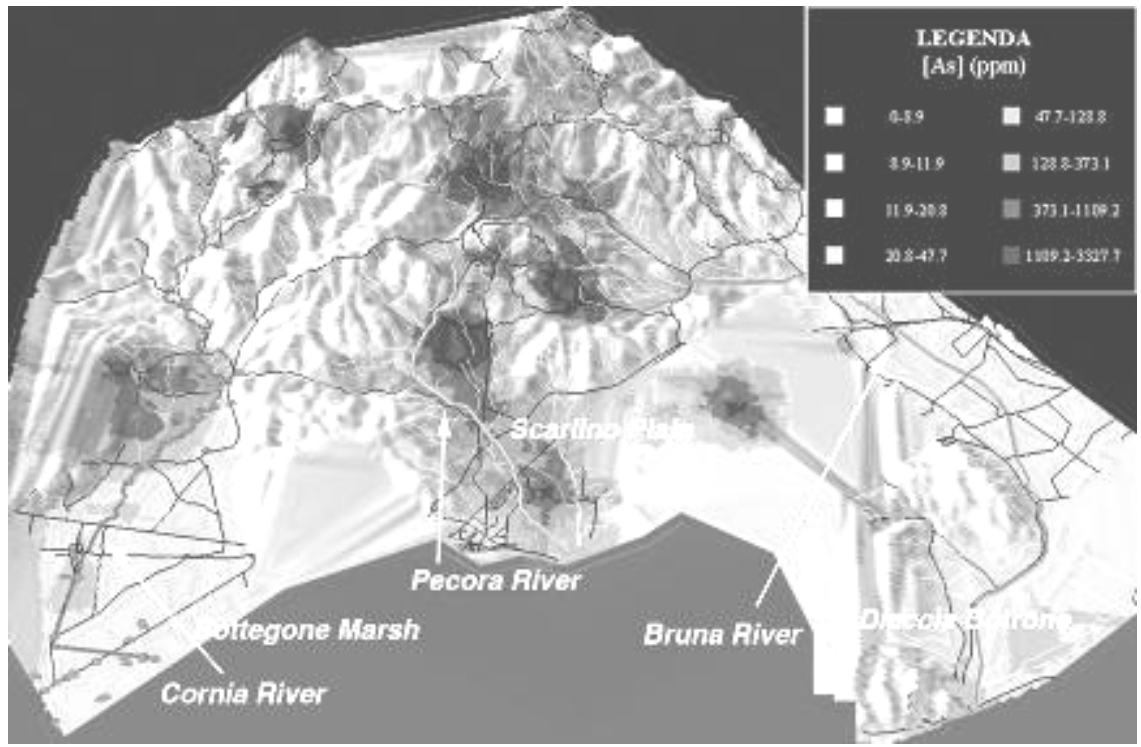

Figure 6: GIS map of the Colline Metallifere area showing concentrations of arsenic in soil and sediments. Darker areas indicate high As concentrations. 


\section{Conclusions}

Data collected over the last years, including data presented in this paper, allowed us to build a geochemical map for Arsenic dispersion in Colline Metallifere area (Fig. 6). The arsenic grid was generated by interpolation of more than 10000 analytical data by an ordinary kriging method.

It is also interesting to compare [As] trend for Bruna and Pecora rivers with results for Cornia. From Figure 7 it is evident that the behaviour of [As] is completely different for the three rivers. Pecora and Bruna shows opposite trends and the highest [As] values are located in correspondence with ancient and modern anthropogenic activities [5,6]. On the Contrary, Cornia River, which flows in a less industrialized area, always presents low arsenic levels.

Arsenic dispersion map, jointly with results for other elements, puts in evidence that natural pollutants levels are significantly lower than the values recorded in the human exploited sites. Moreover wetlands in which the Bruna and Pecora rivers end, did not present Arsenic and other metal anomalies as in the case of the highly industrialized Scarlino plain. Finally, we want to point out that hydrothermal fluxes actually cause high intensity pollution (see the case of $\mathrm{Cr}$ and As), but polluted zones are mostly punctual and limited to and it doesn't seem that hydrothermal fluxes are the main vehicles of pollutants dispersion in the area.

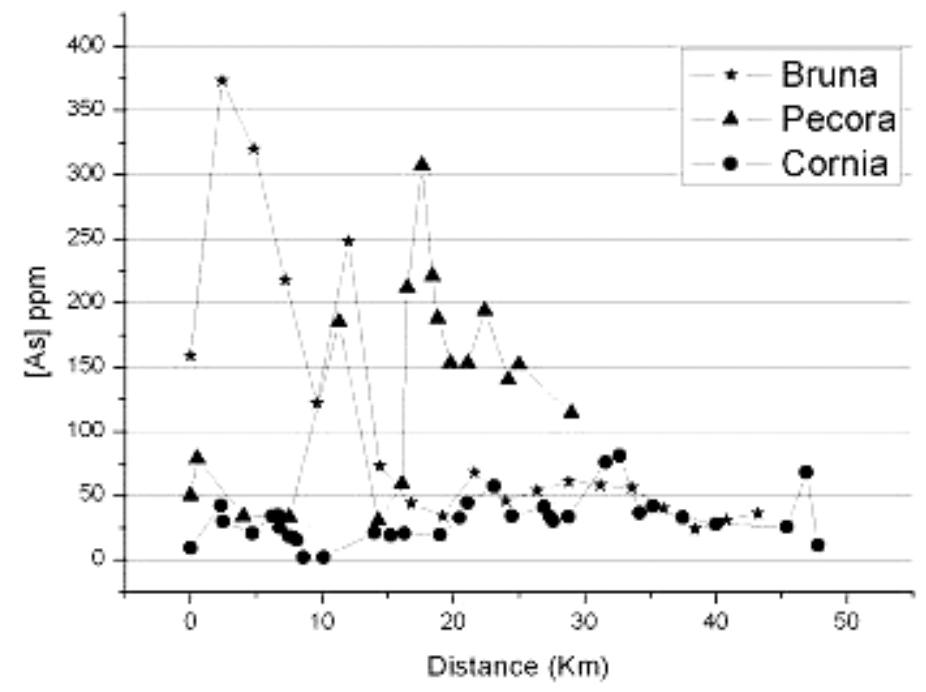

Figure 7: Comparison between [As] trends along the courses of the three main rivers of Colline Metallifere area. 


\section{References}

[1] Adriano D.C., Trace Elements in the Terrestrial Environment. SpringerVerlag, New York: 1986.

[2] a) Cullen W.R. and Reimer K. J. Arsenic speciation in the environment. Chem. Rev. 89, 713-764 (1989); b) Ahman D., Roberts A.L., Krumholz L.R., Morel, F.M.N., Nature, 371, 750, (1994). c) Oremland, S.R., Stolz, J.F. The ecology of Arsenic. Science, 300, 939-944, 2003.

[3] Donati A., Tiezzi E., Marchettini N. On the Arsenic anomaly in the Scarlino county, technical report for the remediation project. 2002.

[4] Picchi, M.P., Fugaro L., Donati A. in Brownfield sites: Assessment, Rehabilitation \& Development, WIT Press, pp. 121-130 2002.

[5] Donati A., Protano G., Riccobono F., Dallai L., Francovich R., Rossi F. and Tiezzi E., Influence of ancient mining settlements on arsenic pollution in the southwest of Tuscany. In Brownfield Sites II, WIT press, pp 183191, 2004.

[6] Donati A., Pulselli F.M., Riccobono F., Dallai L., Francovich R. and Tiezzi E., Ann. Chim., 95(3-4), pp. 161-166, 2005.

[7] a) AQUATER s.p.a. report - Study for the building of a repository for hematite cinders in the Scarlino Plain. 1985; b) ARPAT - Regional Agency for Protection of the Environment - report: Anomalies of Arsenic level in the Scarlino plain: a preliminary study. 2001.

[8] Costagliela, P., Benvenuti, M., Benvenuti, M.G., Innocenti, A., Mascaro, L., Paolieri, M., Rossato, L. and Tanelli, G., Arsenic Distribution in the Quaternary Sediments of the Median Valley of the Pecora Stream (Grosseto, Italy), In Brownfield Sites II, WIT press, pp 201 - 209, 2004. 